\title{
The Virtual Workplace of a Mobile Employee - How Does Vischer's Model Function in Identifying Physical, Functional and Psychosocial Fit?
}

\author{
Ursula Hyrkkänen ${ }^{1, *}$ and Suvi Nenonen ${ }^{2}$ \\ ${ }^{1}$ Aalto University and TUAS, P.O.Box 13300, 00076 Aalto, Finland \\ ${ }^{2}$ Aalto University, P.O.Box 13300, 00076 Aalto, Finland \\ ursula.hyrkkanen@turkuamk.fi
}

\begin{abstract}
The article examines the applicability of Vischer's model of comfort and fit for classifying the features of virtual workplaces used in mobile work. The user-centered model of comfort and fit was applied in the context of systematic literature review. The review showed that the model of environmental fit is useful for more detailed classification of virtual places and spaces. However, it seems that in virtual work the threshold of workplace usability rises from the physical level to the functional level due to accessibility demands. A mobile employee is forced to completely stop working if he/she is not able to connect. Compared to Vischer's model the necessity level of the virtual workplace ascends to cover also the demands of functional fit.
\end{abstract}

Keywords: Virtual workplace, mobile work, comfort factors of virtual workplace.

\section{Introduction}

New developments in information and communication technology have changed the way people approach their life and work. Mobile virtual work is no longer bound to fixed locations as utilizing information and communication technology allows people to function freely in various environments. The employee is considered as mobile, when he works ten hours per week outside of the primary workplace and uses information and communication technologies for collaboration $(1,2)$. Virtual reality $(3)$, as an environment relating to this new 'anytime anywhere work', can be called the virtual workplace. Virtual workplace provides connectivity through different size of devices and is accessed by different interfaces when supporting the performance of both individual and collaborative activities. Internet and intranet provide a platform for both simple (e.g. e-mail) and complex (e.g. collaborative working environments) communication tools. (4)

Our interest is the interrelationship between the physical and the virtual workplace not only in regard to their infrastructure, but also to their social and cultural contexts. Both the prerequisites connected to the virtual workplace and its actual use can be challenging. It could be claimed, for instance, that simultaneous physical and virtual

\footnotetext{
${ }^{*}$ Corresponding author.
} 
co-presence is generally not yet mastered in an effective way and that there still exist certain bottlenecks for a mobile employee entering virtual reality.

Vischer $(5,6)$ has analyzed the physical workplace as a physical, functional and psychological entity in order to identify features related to comfort and fit between a workplace and an employee (fig 1). When environment sets inappropriate or excessive demands to users, in spite of their adaptation and adjustment behaviours, it manifests the concept of misfit. In good fit there is a balance between a person's abilities, skills, degree of control and decision latitude and the work environment's demands, complexity, expectations and challenges. The nature of person-environment transaction arouses the sensation of either comfort or stress. Comfort may be considered as the fit of the user to the environment in the context of work $(5,7$, see also 8).

According to Vischer (5), environmental comfort encompasses three hierarchical categories: physical, functional, and psychological. Physical comfort relates to basic human needs, i.e. safety, hygiene and accessibility. These needs are responded by applying building codes and standards. Functional comfort is defined in terms of support for users` performance of work related tasks and activities. Psychological comfort is related to feelings of belonging, ownership and control over workspace. We have expanded the category of psychological comfort and fit to cover also the social factors, and named the third category psychosocial comfort and fit.

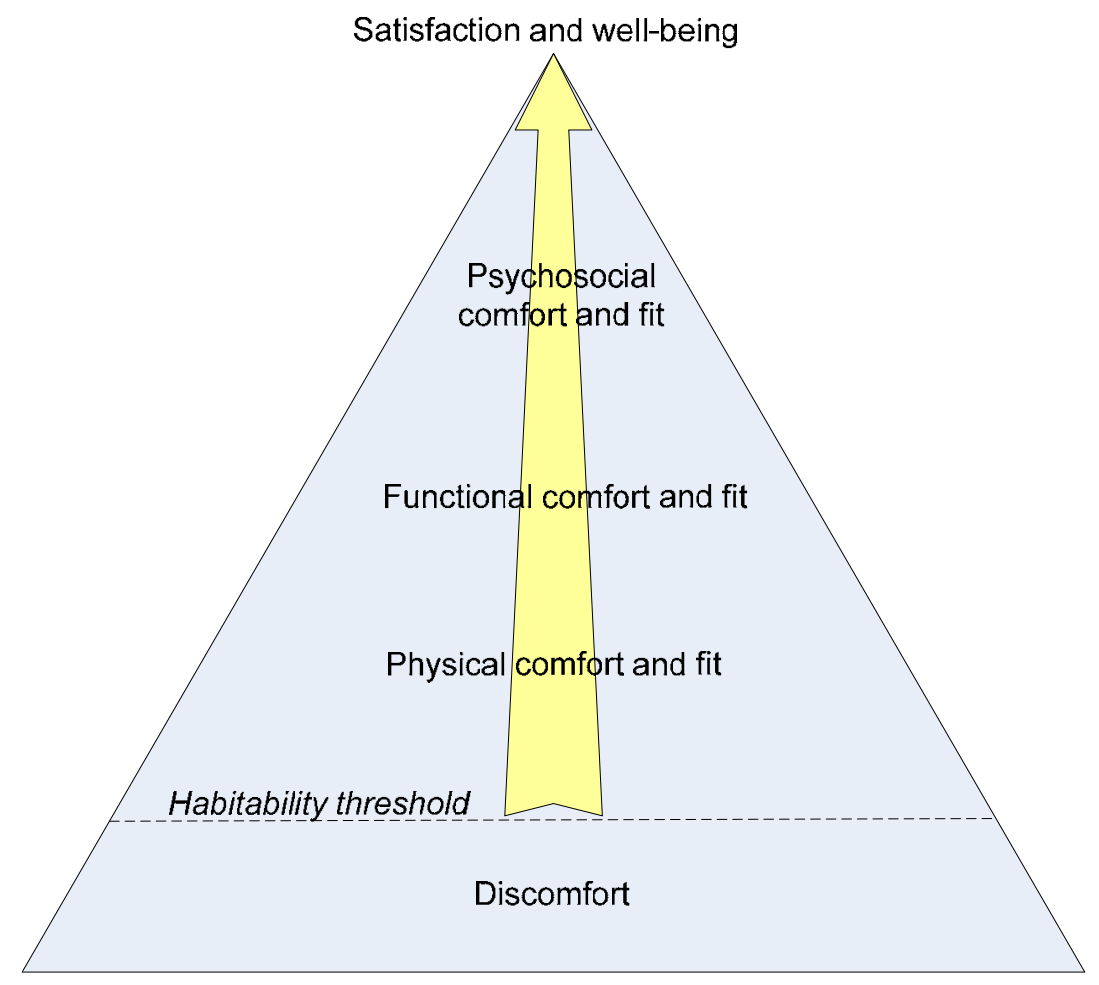

Fig. 1. Vischer's (7) habitability model of comfort and fit (modified) 
Vischer's user-centered model merges environmental aspects with psychological aspects in a dynamic way. Vischer has developed a model for assessing the fit or misfit of physical workspace. The interesting question is whether the virtual workplace can also be captured as a three-level entity and whether this approach provides deeper understanding for managing it.

The purpose of this article is to explore how Vischer's user-centered model of comfort and fit can contribute to identifying the different elements of the virtual workplace, which either hinder or enable productive mobile virtual work processes. By applying Vischer's model, the research questions are:

1. What kind of physical comfort and fit elements can be identified in the virtual workplace of mobile employees?

2. What kind of functional comfort and fit elements can be identified in the virtual workplace of mobile employees?

3. What kind of psychosocial comfort and fit elements can be identified in the virtual workplace of mobile employees?

\section{Method}

The user-centered model of comfort and fit was applied in the context of systematic literature review. First, using a broad list of relevant terms, virtual work, mobile work, nomadic work, virtual workplace and hybrid workspace among others, a systematical search of several electronic multi-disciplinary databases (Scopus, Abi/Inform, Academic Search Elite, Elsevier Science Direct, Web of Science, Google Scholar) was conducted. Of the studies identified, only recent empirical articles (2001-2010) in peer-reviewed journals were selected and included.

Secondly, the outcomes of the 21 included articles were coded and classified according to Vischer's model. First all expressions concerning fit and misfit of mobile virtual work were identified. These expressions were then further classified to the levels of physical, functional and psychosocial factors.

\section{Results}

\subsection{The Elements of Physical Comfort and Fit of the Virtual Workplace of a Mobile Employee}

When considering the physical fit of virtual reality, fourteen of the reviewed articles described the constraints of physical places that mobile workers encounter. Constructions of physical environment blocked and hampered the employees' way to the virtual reality. Many odd places were offered for building up a work station (9), there were no large enough flat surfaces for devices (10), the physical infrastructure for mobile workers was neglected (11) and they had to compete for posts with local workers (11). There may have also been competition for electrical power, if there were not enough power outlets in public places $(11,12,13,14)$. The main reason for these misfit factors was the mobile and multi-local working mode. When executing the anywhere working style, the employee will undoubtedly encounter physical places that have not been are not in the first hand designed primarily for working purposes. 
This is likely to happen for example at airports, in the different means of transportation, in cafeterias or in hotel rooms $(12,13,15,16,17)$.

The physical fit of virtual reality is also a question of its appropriateness to the human sensory system. Especially visual and auditory problems were described in the reviewed articles. For ensuring the success of work, mobile employees carry many tools with them - they carry also redundant tools to be on the safe side. To avoid letting the weight of the burden grow beyond measure, increasingly smaller-sized devices are selected. With small size you inevitably also come to choose small displays - and visual difficulties. $(2,9,12,13,18,11,19,20,21$.)

Noisy environments may disturb concentrated working in virtual reality. Especially in public places, i.e. in trains and in airplanes, the tourists and neighbors beside the mobile worker may disturb the work $(12,15)$. On the other hand, a smooth level of discussing voices e.g. in a cafeteria may help the worker to relax and lose himself in virtual reality $(4,22)$.

Contradictory relation between physical and virtual worlds might cause misfit which may lead to safety risks, e.g. when driving a car $(17,20)$.

According to Vischer $(5,6)$, physical comfort creates the threshold for acceptable workplace. If a building does not meet the basic levels of demands stated in different environment and building standards and codes, it is uninhabitable and unusable. In comparison, the physical misfit of virtual place is caused by the contradictory relation between physical and virtual places and spaces. The main reason for this contradiction is the mobile working mode - i.e. the need to work anywhere. So far there are no standards, codes or rules that would specify the threshold for an acceptable workplace in a bus, train, hotel room or at home. There seldom are rules which would regulate the behaviour of people who use these places for work.

\subsection{The Elements of Functional Comfort and Fit of the Virtual Workplace of a Mobile Employee}

Relating to the functional fit of virtual places, fourteen of the articles presented connectivity problems that caused disturbances and hindrances to virtual work flow and broke it down. Some of the connectivity problems derived from the limited skills of mobile workers in employing virtual settings and infrastructure $(2,10,11,21,23,24)$. Time constraints and tight schedules of mobile employees together with time taking downloads of connections and programs also made it unreasonable to start virtual work $(11,12,13,15,19,20)$. The security regulation of mobile employees`own or their customers`company was reported to hinder the access and functioning in the virtual places $(11,13)$. In some cases the connections were also very expensive and therefore the access was forbidden (12).

According to Vischer (5), the functional fit or misfit of the workplace can be assessed by defining the degree to which occupants can either conserve their attention and energy for their tasks or expend it to cope with poor environmental conditions. In addition, the review observations showed that the functional misfit of a virtual place may lead to total breakdown of work flow. So the threshold of acceptable virtual workplace seems to lie not only at the physical level but also at the functional level. 


\subsection{The Elements of Psycho-Social Comfort and Fit of the Virtual Workplace of a Mobile Employee}

Fifteen articles highlighted problems in the psycho-social fit of virtual place. The problems could be classified into six broad themes, which included controlling simultaneous co- and telepresence $(11,13,23,25,26)$, belonging to physical and virtual communities $(13,23,24)$, need for privacy $(9,10,11,12,13,15)$, expectation of everavailability $(11,13,18,23,25,27)$ and problems of spreading tacit knowledge (23).

In Vischer's environmental comfort model, psychological comfort links psychosocial aspects with the environmental design and management of workspace through the concepts of territoriality, privacy and control $(5,7)$. A sense of territory is associated with feelings of belonging and ownership. Privacy is best understood as the need to exercise control over one's accessibility to others. Environmental control consists of mechanical or instrumental control, and empowerment (7). Instrumental control exists, if the employee masters his furniture, devices and tools. Empowerment as a form of environmental control arises from participation in workplace decision making. When comparing the factors identified from the reviewed articles to Vischer's psychosocial factors, the similarities are evident. Ensuring the psychosocial fit of a virtual workplace is the question of territoriality, privacy and control.

\section{Conclusions}

This review showed that Vischer's model $(5,7)$ of environmental fit is useful for more detailed classification of virtual places and spaces. However, it seems that in virtual work the threshold of habitability rises from the physical level to the functional level due to accessibility demands. The work of a mobile employee will totally stop if the worker is not able to connect. At the same time it should be realized that the concept of usability describes better the threshold of work in virtual world than habitability. So it seems that compared to Vischer 's model the necessity level ascends to cover also the demands of functional fit (see fig. 2).

The use of the model also made it evident that in order to develop well-functioning virtual workplaces for mobile employees, broad attention should be paid to the whole system, within which employees confront their duties on different locations. Gaining comprehensive understanding about the context in which a given task is performed starts by forming questions first on physical place and later on psychosocial themes. Being such a vast field, the process demands profound multidisciplinary collaboration of different actors in organizations and support functions. The inspection of different fit levels is a useful tool for helping different authorities to explain their expertise in relation to other authorities. Gaps in management may also be demonstrated.

According to this review with Vischer's model as a frame of reference, it can be stated that

- at the level of physical fit, building codes and standards should be expanded to cover also the needs generated from the new working modes i.e. mobile work

- at the level of functional fit, the access creates the threshold of work. Moreover, the questions concerning the infrastructure, easiness of connecting signals as well as of finding help and support in using information technology are essential 
- enhancing the fit at the psychosocial level: the mixture of physical and virtual worlds and simultaneous existence in both should be more effectively understood and supported as well as the integrated design, which seamlessly combine the physical and the virtual places need to be developed further.

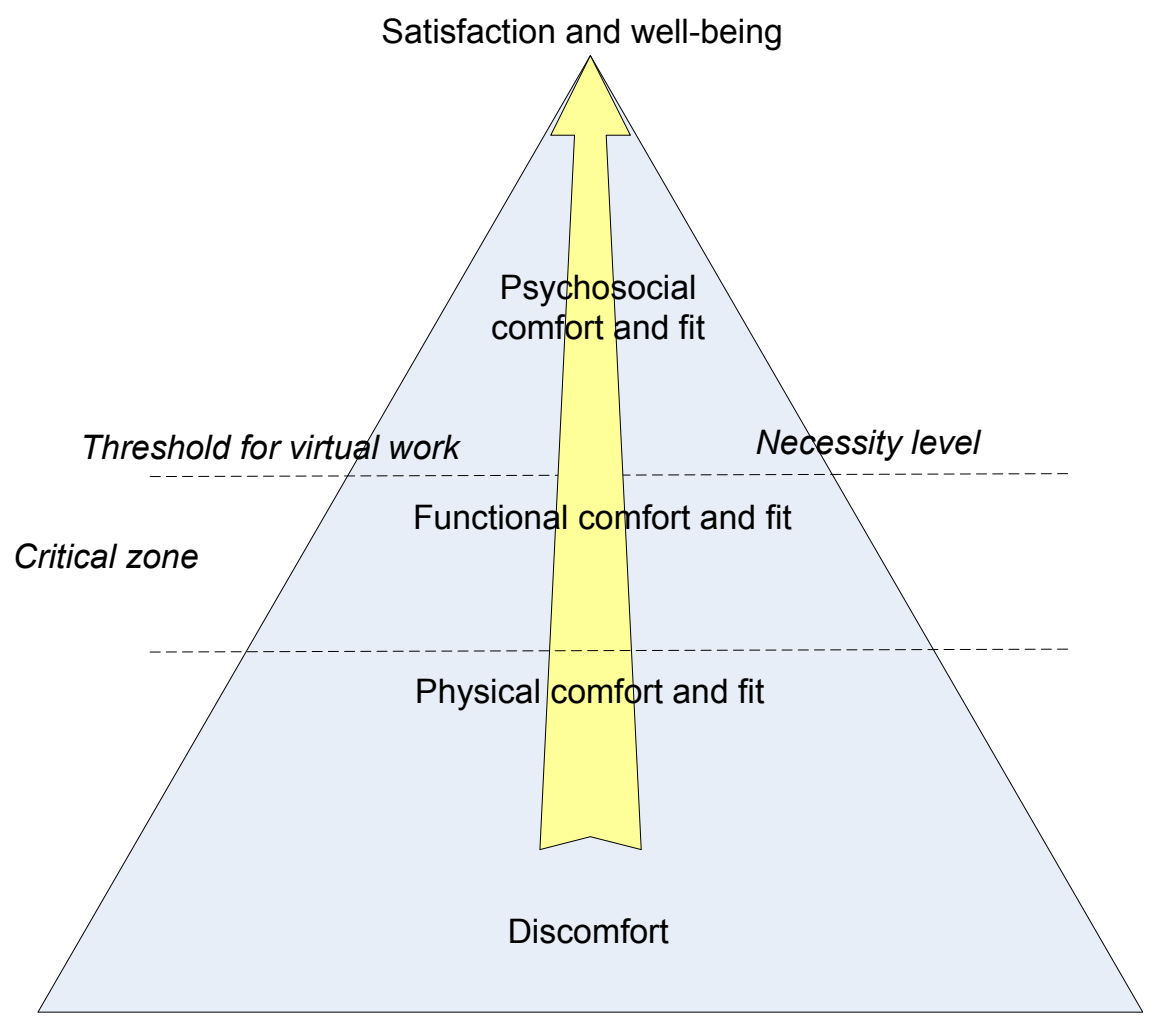

Fig. 2. Vischer's (2005) model of comfort and fit modified for assessing virtual work places

\section{References}

1. Gareis, K., Lilischkis, S., Mentrup, A.: Mapping the Mobile eWorkforce in Europe. In: Andriessen, J.H.E., Vartiainen, M. (eds.) Mobile Virtual Work. A New Paradigm?, pp. 45-69. Springer, Heidelberg (2006)

2. Vartiainen, M., Hyrkkänen, U.: Changing requirements and mental workload factors in mobile multi-location work. New Technology, Work and Employment 25(2), 117-135 (2010)

3. Fox, J., Arena, D., Bailenson, J.N.: Virtual reality. A Survival Guide for the Social Scientist. Journal of Media Psychology 21(3), 95-113 (2009)

4. Nenonen, S., Airo, K., Bosch, P., Fruchter, R., Koivisto, S., Gerberg, N., Rothe, P., Ruohomäki, V., Vartiainen, M.: Managing Workplace Resources for Knowledge Work, the final report of ProWork-project (2009),

http: / / www . proworkproject.com/prowork/final-report

5. Vischer, J.C.: The effects of physical environment on job performance: towards a theoretical model of workspace stress. Stress and Health 23, 175-184 (2007) 
6. Vischer, J.C.: Towards an Environmental Psychology of Workspace: How People are Affected by Environments for Work. Architectural Science Review 51(2), 97-108 (2008)

7. Vischer, J.C.: Space meets status. Designing workplace performance. Routledge, New York (2005)

8. Dainoff, M.J., Mark, L.S., Ye, L., Petrovic, M.: Forget About Aesthetics in Chair Design: Ergonomics Should Provide the Basis for Comfort. In: Dainoff, M.J. (ed.) HCII 2007 and EHAWC 2007. LNCS, vol. 4566, pp. 19-25. Springer, Heidelberg (2007)

9. Hislop, D., Axtell, C.: To infinity and beyond?: workspace and the multi-location worker. New Technology, Work and Employment 24(1), 60-75 (2009)

10. Perry, M., Brodie, J.: Virtually connected, practically mobile. In: Andriessen, Vartiainen (eds.) Mobile Virtual Work, pp. 97-127. Springer, Heidelberg (2006)

11. Mark, G., Su, N.M.: Making infrastructure visible for nomadic work. Pervasive and Mobile Computing (2010),

http: / / www. elsevier.com/locate/pmc, doi:10.1016/j.pmcj.2009.12.004

12. Axtell, C., Hislop, D., Whittaker, S.: Mobile technologies on mobile spaces. Findings from the context of train travel. International Journal of Human-Computer Studies 66, 902-915 (2008)

13. Brown, B., O‘Hara, K.: Place as a practical concern of mobile workers. Environment and Planning 35, 1565-1587 (2003)

14. Forlano, L.: Working on the move. The social and digital ecologies of mobile work place. In: Hislop (ed.) Mobility and Technology in the Workplace, pp. 28-42. Routledge, New York (2008)

15. Breure, A., van Meel, J.: Airport offices: Facilitating nomadic worker. Facilities 21(7/8), 175-179 (2003)

16. Laurier, E.: Doing office work on the motorway. Theory, Culture \& Society 21(4/5), 261277 (2004)

17. Laurier, E., Philo, C.: The region in the boot: mobilizing lone subjects and multiple object. Environment and Planning D 21, 85-106 (2003)

18. Felstead, A., Jewson, N., Walters, S.: Changing Places of Work. Palgrave Macmilan, New York (2005)

19. Perry, M., O'Hara, K., Sellen, A., Brown, B., Harper, R.: Dealing with Mobility: Understanding access anytime, anywhere. ACM Transactions on Computer-Human Interaction (TOCHI) 8(4), 323-347 (2001)

20. Perry, M., Brodie, J.: Virtually connected, practically mobile. In: Andriessen, Vartiainen (eds.) Mobile Virtual Work, pp. 97-127. Springer, Heidelberg (2006)

21. Venezia, C., Allee, V.: Supporting mobile worker networks: components for effective workplaces. Journal of Corporate Real Estate 9(3), 168-182 (2007)

22. Forlano, L.: Anytime? Aywhere?: Reframing Debates Around Municipal Wireless Networking. The Journal of Community Informatics 4(1) (2008), http://cijournal.net/index.php/ciej/article/view/438/401

23. Hallford, S.: Hybrid workspace: re-spatialisations of work, organization and management. New Technology, Work and Employment 20(1), 19-33 (2005)

24. Mann, S., Holdsworth, L.: The psychological impact of teleworking: stress, emotions and health. New Tecnology, Work and Employment 18(3), 196-211 (2003)

25. Green, N.: On the Move. Technology, Mobility, and the Mediation of Social Time and Space. The Information Society 18, 281-292 (2002)

26. Tietze, S., Musson, G.: Recasting the home-work relationship: A case of mutual adjustment? Organization Studies 26(9), 1331-1352 (2005)

27. Tietze, S., Musson, G.: When work meets home. Temporal flexibility as lived experience. Time \& Society 11(2/3), 315-334 (2002) 